\title{
chaJOPEN
}

\section{Quality of end-of-life communication in 2 high-risk ICU cohorts: a retrospective cohort study}

\author{
Tammy L. Pham MPAS MSc, Allan Garland MD MA
}

Abstract

Background: Factors influencing the quality of end-of-life communication are relevant to improving end-of-life care. We assessed the quality of end-of-life communication and influencing factors in 2 intensive care unit (ICU) cohorts at high risk of death: patients living in nursing homes and those on extracorporeal membrane oxygenation (ECMO).

Methods: This retrospective cohort study included admissions to 4 ICUs in Winnipeg, Manitoba, from 2000 to 2017 . We identified cohorts and influencing factors from the Winnipeg ICU database and by manual chart review. We assessed quality of end-of-life communication using 18 validated, binary quality indicators to calculate a weighted, scaled, composite score (range 0-100). We used median regression to identify factors associated with the composite score.

Results: The ECMO cohort $(n=109)$ was younger than the nursing home cohort $(n=230)$, with longer hospital stays and higher disease severity. Mean composite scores of end-of-life communication were extremely low in both cohorts (mean 48.5 [standard error of the mean (SEM) 1.7] for the nursing home cohort, 49.1 [SEM 2.5] for the ECMO cohort). Patient characteristics associated with higher median composite scores were older age (5.0 per decade, 95\% confidence interval [Cl] 2.1-7.8) and lower (worse) Glasgow Coma Scale (GCS) scores (1.8 per GCS point, $95 \% \mathrm{Cl}$ 0.5-3.2). The median composite score rose significantly over time (1.7 per year, 95\% Cl 0.5-2.8).

Interpretation: The quality of end-of-life communication in ICUs is poor, and factors associated with better prognosis are also associated with worse communication. Direct and early communication should occur with all patients in the ICU and their surrogates, not just those who are believed most likely to die.

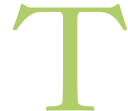
imely receipt of honest, comprehensible information about prognosis and care options has been identified as a priority by critically ill patients and their families but is not always provided. ${ }^{1,2}$ End-of-life communication occurs between a care team and an individual with a foreseeably limited life expectancy and those who speak for that individual. As defined by Sinuff and colleagues, end-of-life communication strives to create "a shared understanding about a person's values and care preferences that will lead to a plan of care that is congruent with these values and preferences." 3

However, problems in end-of-life communication persist for seriously ill, hospitalized adults, including in intensive care units (ICUs), where $19 \%$ of Canadians die..$^{4-7}$ Missing or inadequate communication on advance care planning and goals of care often leads to more aggressive care than desired by patients. ${ }^{8-13}$ Most discussions fail to include issues of importance to patients that help them make end-of-life decisions, such as long-term risks to their physical, cognitive and social functioning. ${ }^{14,15}$

Few hospitals routinely collect information about the quality of communication regarding palliative and end-oflife care. ${ }^{16}$ Widespread and large variation in end-of-life decision-making and practice in ICUs $s^{12,14,17,18}$ suggest that factors outside of patient-centred care influence them, providing strong, indirect evidence of variation in end-of-life communication. Indeed, poor communication with the ICU team has been found to be the most common complaint among families of people who die in ICUs. ${ }^{1,2}$ Knowing the factors that influence the quality of end-of-life communication is important to improve end-of-life care. Identification of gaps in end-of-life communication is needed to inform interventions to improve patient-centred outcomes. ${ }^{19}$ However, relatively few studies have directly assessed end-of-life communication.

Across ICUs in Canada, older patients from nursing homes consistently have poor ICU outcomes, with most dying in hospital or soon after discharge. ${ }^{20,21}$ Patients with severe cardiovascular or respiratory failure placed on extracorporeal

\section{Competing interests: None declared.}

This article has been peer reviewed.

Correspondence to: Tammy Pham, phamt347@myumanitoba.ca CMAJ Open 2021. DOI:10.9778/cmajo.20200146 
membrane oxygenation (ECMO) face an invasive procedure requiring insertion of large vascular catheters, with high rates of complications and death. ${ }^{22,23}$ Thus, these specific cohorts reasonably mandate a high level of attention to end-of-life communication, and they represent different population subgroups in terms of patient characteristics such as age and burden of comorbidity. ${ }^{20,24}$ In this study, we aimed to assess the quality of, and factors associated with, end-of-life communication among these 2 groups of ICU patients.

\section{Methods}

\section{Study design and population}

We conducted a retrospective cohort study in the Winnipeg Health Region of Manitoba, Canada. Its population was 778000 in 2018, representing $57 \%$ of the provincial population. ${ }^{25}$ We hypothesized that, given the poor ICU outcomes of patients from nursing homes, end-of-life communication would be better for them than for patients on ECMO.

Of the 11 adult ICUs across 6 hospitals in the health region, we included data from the 2 tertiary hospitals capable of performing ECMO. These hospitals contain 4 ICUs: the Medical Intensive Care Unit and the Surgical Intensive Care Unit at the Winnipeg Health Sciences Centre, and the Medical Surgical Unit and the Cardiac Surgical Unit at St. Boniface Hospital.

We identified 2 separate cohorts of patients admitted between Jan. 1, 2000, and Dec. 31, 2017, to any of the 4 ICUs. The nursing home cohort comprised all provincial residents aged 50 years and older identified as having resided in nursing homes before hospitalization. The ECMO cohort comprised all provincial residents aged 18 years and older identified as having received either arteriovenous or venovenous ECMO at any point in their ICU stay. For both cohorts, we considered only the first eligible hospitalization. Because of the potential for insufficient opportunity to explore end-of-life decisionmaking fully, we excluded patients with ICU lengths of stay less than 24 hours.

\section{Data sources}

We used 2 data sources. The Winnipeg ICU Database is a clinical database that captures all adult ICU admissions in the Winnipeg Health Region since 1999, encompassing 93\% of all high-intensity adult ICU admissions in Manitoba. ${ }^{26}$ It contains data on diagnoses (including those at admission, acquired diagnoses and comorbidities), severity of acute illness, invasive procedures performed and disposition. ${ }^{26}$ These data, which have been used extensively for 30 years, are directly abstracted from ICU medical records by dedicated data collectors, and are subjected to numerous checks of internal consistency. ${ }^{26}$

One author (T.P.) also performed manual review of hospital charts using a data abstraction tool created in Microsoft Access. To assess the quality of chart review data extraction, we reabstracted and recalculated the unweighted score of a $10 \%$ random sample of all abstracted charts. We also assessed test-retest (intrarater) reliability using the Cohen $\kappa$ coefficient, where a value greater than 0.7 was considered satisfactory agreement. ${ }^{27}$

\section{Variables and outcomes}

We extracted the following elements for both cohorts from the ICU database: age, sex, year of admission, prehospital domicile type, ICU admission diagnosis, hospital length of stay, hospital disposition, the Glasgow Coma Scale (GCS) score $^{28}$ and the Acute Physiology and Chronic Health Evaluation (APACHE) II score, including its Acute Physiology Score (APS). ${ }^{29}$ The GCS is a measure of the extent of impaired consciousness, and the APACHE II score and the APS are measures of acute illness severity. The APS is the sum of elements, including GCS. We explicitly included the GCS in our models and, to avoid collinearity, removed it from the APS to generate the APS-neuro score, which has been previously used. ${ }^{30}$

In the ICU database, ICU admission diagnoses were categorized as cardiac, endocrine, gastrointestinal, genitourinary, hematologic, infectious, inflammatory, metabolic, musculoskeletal, neoplastic, neuropsychiatric, obstetrical, otolaryngological, renal, respiratory or vascular. Diagnoses could also be categorized as an overdose or poisoning, trauma or "other." We identified patients who resided in a nursing home from detailed data supplied by the provincial department of health (for patients from 2006 onward) or from less detailed data supplied by the regional health authority (for patients before 2006).

For the ECMO cohort, we also captured the type of ECMO used, urban or rural residence and socioeconomic status. We derived residence and socioeconomic status from residential postal codes; we measured socioeconomic status as the average family income quintile from the 2006 Canadian census. ${ }^{31}$ This information was not meaningfully available for patients in the nursing home cohort, as their postal codes refer to the nursing homes in which they were living.

One team member (T.P.) conducted manual chart review, from which we obtained the elements of a previously described and validated measure for the quality of end-of-life communication. This measure is a composite score of the presence or absence of 18 quality indicators, including 13 items on the goal of care communication and 5 documentation items, described by Sinuff and colleagues ${ }^{3,21}$ (Appendix 1, Supplementary Table 2, available at www.cmajopen. $\mathrm{ca} /$ content/9/2/E570/suppl/DC1). We calculated the composite weighted percent score, our primary outcome, as the sum of these 18 items, weighted by the importance scores assigned in the creation of this instrument ${ }^{3}$ and rescaled it to a range of $0-100$, with higher values representing better quality of end-of-life communication. As secondary outcomes, we calculated the weighted scores from the goals of care communication and documentation submeasures. We classified the quality of scaled scores as extremely low $(<50)$, low (50-74), medium (75-84) or high (85-100).

We also used chart review to establish the number of days between ICU admission and the first documentation in the chart of the level of care (elapsed time to advance care planning), and level of care. In Manitoba, provincial policy defines 3 levels of care, in descending order of aggressiveness: resuscitation (i.e., no types of medical interventions were to 
be withheld), medical (i.e., allowing application of all interventions except resuscitation) and comfort care only. ${ }^{32}$ As levels of care may change during a hospital stay, we recorded the least aggressive level assigned at any point in the ICU.

\section{Statistical analysis}

For the composite and subscale measure scores, we compared the unadjusted means and medians of the nursing home and ECMO cohorts with the Student $t$ test and the Mann-Whitney test, respectively. We compared the frequency of each of the 18 quality indicators for the nursing home and ECMO cohorts using Fisher exact tests.

We used multivariable regression to identify factors associated with the quality of end-of-life communication. As our data violated the linear regression requirements of normality and homoscedasticity of the residuals, ${ }^{33}$ we used median regression ${ }^{34}$ with standard errors via bootstrapping with 100 replications. We included all available variables, except for those expected to strongly confound end-of-life communication (i.e., level of care, length of stay and hospital death). We also performed median regression for the ECMO cohort, including the additional variables of ECMO type, socioeconomic status and urban or rural residence.

We performed 2 sensitivity analyses. First, as the weightings of the 18 items were derived from expert opinions, we reran the median regression with equal weighting of all items. Second, as identification of patients from nursing homes was less reliable before 2006 and clearly missed many such transfers, we reran the median regression, excluding the years 2000-2005.

We used Stata 15 for statistical analysis (StataCorp) and considered $p$ values less than 0.05 as significant. To account for the multiple comparisons inherent to multivariable regression, we used the step-up procedure of Simes for controlling the false discovery rate at less than $5 \% .{ }^{35}$

\section{Ethics approval}

This study was approved by the Health Research Ethics Board of the University of Manitoba.

\section{Results}

For the nursing home cohort, we reviewed 230 charts of the 232 that met inclusion and exclusion criteria. For the ECMO cohort, we reviewed 109 of 110 charts. The remaining 2 nursing home charts and $1 \mathrm{ECMO}$ chart were not available in the medical records departments at the time of chart review. The weighted $\kappa$ coefficient was 0.95 , showing very high agreement between first and second data extraction by the same data extractor.

Patient and illness characteristics are listed in Table 1. The ECMO cohort was younger than the nursing home cohort, with longer hospital stays, longer elapsed time to advance care planning and worse disease severity indices (APACHE II, GCS, APS, APS-neuro).

The mean composite score for quality of end-of-life communication (Table 2) was extremely low in both cohorts. For the composite score, there was no significant difference between the 2 cohorts, but the ECMO cohort did have a significantly lower documentation subscore (Table 2).

Year of admission, age and GCS score were significantly associated with the median composite communication score (Table 3). The composite score rose over time, by 1.7 points yearly. Composite scores increased significantly with age ( 5 points per decade) and with lower GCS scores (1.8 points for each GCS point lower, representing more severe presentations). After adjustment for covariates, the quality of end-oflife communication was similar for the nursing home and ECMO cohorts. The additional variables of socioeconomic status and location of residence were not associated with the composite quality score in the ECMO cohort (Appendix 1, Supplementary Table 1).

Among the 18 individual binary quality items (Appendix 1, Supplemental Table 2), only 4 items differed in frequency between our 2 cohorts, with 2 in each direction. In sensitivity analyses, equal weighting of the 18 items, and excluding the years 2000-2005 gave similar findings (Appendix 1, Supplementary Tables 3 and 4).

\section{Interpretation}

Two cohorts of ICU patients both experienced extremely low quality of end-of-life communication. These 2 cohorts both had high disease severity and rates of hospital death, but were otherwise disparate in characteristics such as age and the burden of comorbid illness. ${ }^{20,24}$ However, end-of-life communication did improve over time. Patients in the ICU with characteristics associated with better prognosis, specifically younger age and better neurologic function, experienced systematically worse end-of-life communication. The magnitude of variation of median score by these factors is about $10 \%$ for a 5 -point difference in GCS scores or a 20 -year difference in age. This phenomenon could explain the even lower average composite score observed among less acutely ill patients by Heyland and colleagues ${ }^{21}$ in their study of 12 Canadian hospitals.

The observation that ICU clinicians perform worse in communicating about end-of-life care for patients who they perceive as less likely to die is problematic. Beyond the influence of age, ${ }^{14}$ we are unaware of other studies that have identified this phenomenon; thus, our study adds more insight into the problems of end-of-life care in ICUs. ${ }^{11,12,36-38}$ Because it is difficult to determine prognoses for ICU patients ${ }^{39}$ it means that critically ill patients with apparently better prognoses are exposed to worse end-of-life communication, which in turn puts them at higher risk of receiving care that fails to take their preferences and values into account, ${ }^{40,41}$ and fails to be concordant with those wishes. ${ }^{7,21}$

There is a paucity of interventional studies attempting to improve end-of-life communication in ICUs. Wessman and colleagues conducted a before-and-after study of a multidisciplinary intervention in a single ICU in the United States, including creation of a goals of care team, communication tools, pamphlets, standardized order sets and education. ${ }^{42}$ 
Table 1: Patient and illness characteristics among 2 ICU cohorts, 2000-2017

\begin{tabular}{|c|c|c|}
\hline \multirow[b]{2}{*}{ Variable } & \multicolumn{2}{|c|}{ No. $(\%)$ of cohort ${ }^{\star}$} \\
\hline & $\begin{array}{c}\text { Nursing home } \\
n=230\end{array}$ & $\begin{array}{l}\text { ECMO } \\
n=109\end{array}$ \\
\hline \multicolumn{3}{|l|}{ Age, yr } \\
\hline Mean \pm SD & $72.0 \pm 10.6$ & $51.8 \pm 15.8$ \\
\hline Median (IQR) & $73(64-80)$ & $56(44-64)$ \\
\hline Sex, female & $103(44.8)$ & $45(41.3)$ \\
\hline \multicolumn{3}{|l|}{ Year of admission } \\
\hline 2000-2004 & $5(2.2)$ & 0 \\
\hline $2005-2009$ & $70(30.4)$ & $8(7.3)$ \\
\hline 2010-2014 & $88(38.3)$ & $60(55.0)$ \\
\hline 2015-2017 & $67(29.1)$ & $41(37.6)$ \\
\hline \multicolumn{3}{|l|}{ Location of residence } \\
\hline Urban & & $77(70.6)$ \\
\hline Rural & & $26(23.9)$ \\
\hline Out-of-province or nursing home resident & & $6(5.5)$ \\
\hline \multicolumn{3}{|l|}{ Socioeconomic status quintile } \\
\hline 1 (lowest income) & & $29(28.2)$ \\
\hline 2 & & $24(23.3)$ \\
\hline 3 & & $11(10.7)$ \\
\hline 4 & & $17(16.5)$ \\
\hline 5 (highest income) & & $22(21.4)$ \\
\hline \multicolumn{3}{|l|}{ Category of primary diagnosis at admission } \\
\hline Cardiovascular & $52(21.7)$ & $59(54.1)$ \\
\hline Infectious & $78(33.9)$ & $26(23.9)$ \\
\hline Respiratory & $47(20.4)$ & $23(21.1)$ \\
\hline All others & $55(23.9)$ & $1(0.9)$ \\
\hline \multicolumn{3}{|l|}{ Disease severity } \\
\hline APACHE II score, mean \pm SD & $22.4 \pm 6.4$ & $28.5 \pm 8.1$ \\
\hline APACHE II score, median (IQR) & $22(17-27)$ & $27(22-35)$ \\
\hline GCS, mean \pm SD & $12.0 \pm 3.4$ & $8.3 \pm 4.6$ \\
\hline GCS, median (IQR) & $13(10-15)$ & $7(3-13)$ \\
\hline APS, mean \pm SD & $12.9 \pm 4.8$ & $18.7 \pm 6.0$ \\
\hline APS, median (IQR) & $13(9-16)$ & $18(14-23)$ \\
\hline APS-neuro score, mean \pm SD & $10.1 \pm 5.4$ & $12.0 \pm 7.1$ \\
\hline APS-neuro score, median (IQR) & $10(6-14)$ & $12(7-17)$ \\
\hline \multicolumn{3}{|l|}{ Elapsed ACP time, $d$} \\
\hline Mean \pm SD, & $2.9 \pm 6.2$ & $9.1 \pm 16.3$ \\
\hline Median (IQR) & $1.0(1-2)$ & $4.0(1-13)$ \\
\hline \multicolumn{3}{|l|}{ ECMO type } \\
\hline Venovenous with or without arteriovenous & & $16(14.7)$ \\
\hline Arteriovenous only & & $91(83.5)$ \\
\hline \multicolumn{3}{|l|}{ Level of care $†$} \\
\hline Resuscitation & $56(24.3)$ & $44(40.4)$ \\
\hline Medical & $90(39.1)$ & $6(5.5)$ \\
\hline Comfort care & $57(24.8)$ & $45(41.3)$ \\
\hline Missing & $27(11.8)$ & $14(12.8)$ \\
\hline \multicolumn{3}{|l|}{ Hospital length of stay, $d$} \\
\hline Mean \pm SD & $20.1 \pm 33.4$ & $33.8 \pm 35.1$ \\
\hline Median (IQR) & $11(6-19)$ & $20(9-48)$ \\
\hline Hospital death & $69(30.0)$ & $51(46.8)$ \\
\hline \multicolumn{3}{|c|}{$\begin{array}{l}\text { Note: APACHE = acute physiology and chronic health evaluation, APS }=\text { acute physiology score, APS-neuro score = APS score with neurologic component removed } \\
\text { ECMO = extracorporeal membrane oxygenation, elapsed ACP time = elapsed advance care planning time (i.e., interval between ICU admission and first chart } \\
\text { documentation of the level of care), GCS = Glasgow Coma Scale, ICU = intensive care unit, IQR = interquartile range, } S D=\text { standard deviation. } \\
\text { *Unless indicated otherwise. } \\
\text { †Least aggressive level of care recorded. }\end{array}$} \\
\hline
\end{tabular}




\begin{tabular}{|c|c|c|c|}
\hline Weighted scores* & $\begin{array}{l}\text { Nursing home } \\
\text { cohort }\end{array}$ & ECMO cohort & $p$ value $\dagger$ \\
\hline \multicolumn{4}{|c|}{ Composite measure of EOL communication* } \\
\hline Mean \pm SD & $48.5 \pm 25.8$ & $49.1 \pm 25.9$ & 0.67 \\
\hline Median (IQR) & $56.2(28.4-73.8)$ & $52.2(27.5-68.9)$ & 0.86 \\
\hline Mean \pm SD & $39.9 \pm 28.5$ & $44.7 \pm 29.1$ & 0.17 \\
\hline Median (IQR) & $43.4(8.2-63.5)$ & $50.0(15.2-70.5)$ & 0.14 \\
\hline \multicolumn{4}{|c|}{ Documentation subscore } \\
\hline Mean \pm SD & $70.9 \pm 28.2$ & $60.3 \pm 27.1$ & 0.001 \\
\hline
\end{tabular}

Table 3: Median regression results for composite measure of end-of-life communication among 2 ICU cohorts, 2000-2017

\begin{tabular}{|c|c|}
\hline Variable & Coefficient $(95 \% \mathrm{Cl})$ \\
\hline \multicolumn{2}{|l|}{ Cohort } \\
\hline Nursing home cohort & Reference \\
\hline ECMO cohort & $-0.56(-13.15$ to 12.02$)$ \\
\hline Age (per year) & $0.50(0.21 \text { to } 0.78)^{*}$ \\
\hline \multicolumn{2}{|l|}{ Sex } \\
\hline Male & Reference \\
\hline Female & $-2.29(-12.21$ to 7.63$)$ \\
\hline Year of admission (per year) & $1.69(0.54 \text { to } 2.84)^{*}$ \\
\hline $\begin{array}{l}\text { Glasgow Coma Scale score (per } \\
\text { point) }\end{array}$ & $-1.84(-3.21 \text { to }-0.47)^{\star}$ \\
\hline APS-neuro score (per point) & $0.72(-0.18$ to 1.63$)$ \\
\hline \multicolumn{2}{|l|}{$\begin{array}{l}\text { Category of primary diagnosis at } \\
\text { admission }\end{array}$} \\
\hline Cardiovascular & Reference \\
\hline Infectious & $0.93(-9.02$ to 10.88$)$ \\
\hline Respiratory & $-8.56(-24.16$ to 7.05$)$ \\
\hline Other & $-3.42(-15.76$ to 8.92$)$ \\
\hline \multicolumn{2}{|c|}{$\begin{array}{l}\text { Note: } \mathrm{APS} \text {-neuro score }=\text { acute physiologic score with neurologic component } \\
\text { removed, } \mathrm{Cl}=\text { confidence interval, } \mathrm{ECMO}=\text { extracorporeal membrane } \\
\text { oxygenation } \\
{ }^{\circ} p \text { value significant after adjustment for multiple comparisons using the } 0.05 \\
\text { false discovery rate threshold. }\end{array}$} \\
\hline
\end{tabular}

However, they did not evaluate actual end-of-life communication or care.

Direct and early communication should occur with all ICU patients and their surrogates. Existing guidelines and expert opinion ${ }^{2,43}$ highlight the necessity for a shared decisionmaking model.

\section{Limitations}

Although problems with end-of-life care and communication for ICU patients appear to be ubiquitous,,${ }^{72,14,44-47}$ our study has a moderate sample size and derives from 2 patient cohorts in 4 ICUs at 2 hospitals in a single Canadian city. Although it cannot be assumed that our findings generalize to other ICU cohorts, the disparate characteristics of these 2 cohorts is not consistent with our findings being particular to a given type of patient or clinical situation. The question of generalizability of our findings beyond these few ICUs is a concern, and, beyond the above-noted ubiquity of problems in this area, can be directly addressed only by additional studies in different jurisdictions. By using manual review of hospital charts, we could not include end-of-life conversations that occurred, but were not documented. This is a fundamental challenge of doing research in this area. However, reassuringly, another study interviewed hospitalized patients and their families and found even lower scores on the same communication elements. ${ }^{21}$ The thresholds for scale interpretation are somewhat arbitrary. We began with the idea that all 18 scale elements are important, as judged by the expert group in the original description. ${ }^{3}$ Thus, we believe that a perfect score of 100 is desirable and attainable, producing a reasonable decision that a score of less than 50 is "extremely low." Only 1 team member conducted chart reviews and we did not assess interrater reliability.

\section{Conclusion}

The quality of end-of-life communication in ICUs is poor, and factors associated with better prognosis are also associated with worse communication. Direct and early communication should occur with all ICU patients and their surrogates, not just those who are believed most likely to die, preferably using a shared decision-making model. More research is needed to uncover practical and sustainable interventions to accelerate improvement. 


\section{References}

1. Heyland DK, Cook DJ, Rocker GM, et al. Defining priorities for improving end-of-life care in Canada. CMA7 2010;182:E747-52.

2. Wood GJ, Chaitin E, Arnold RM. Communication in the ICU: holding a family meeting. In: Parsons PE, Schwenk TL, editors. Waltham (MA): UpToDate; 2020.

3. Sinuff T, Dodek P, You JJ, et al. Improving end-of-life communication and decision making: the development of a conceptual framework and quality indicators. 7 Pain Symptom Manage 2015;49:1070-80.

4. Heyland DK, Lavery JV, Tranmer TE, et al. Dying in Canada: Is it an institutionalized, technologically supported experience? 7 Palliat Care 2000; 16(Suppl):S10-6.

5. Gruneir A, Mor V, Weitzen S, et al. Where people die: a multilevel approach to understanding influences on site of death in America. Med Care Res Rev 2007;64:351-78.

6. Access to Palliative Care in Canada. Ottawa: Canadian Institute for Health Information; 2018. Available: www.cihi.ca/sites/default/files/document/ access-palliative-care-2018-en-web.pdf (accessed 2019 Nov. 24).

7. Lee RY, Brumback LC, Sathitratanacheewin S, et al. Association of physician orders for life-sustaining treatment with ICU admission among patients hospitalized near the end of life. FAMA 2020;323:950-60.

8. Gramelspacher GP, Zhou XH, Hanna MP, et al. Preferences of physicians and their patients for end-of-life care. 7 Gen Intern Med 1997;12:346-51.

9. Wright AA, Zhang B, Ray A, et al. Associations between end-of-life discussions, patient mental health, medical care near death, and caregiver bereavement adjustment. FAMA 2008;300:1665-73.

10. Allison TA, Sudore RL. Disregard of patients' preferences is a medical error: comment on "Failure to engage hospitalized elderly patients and their families in advance care planning." FAMA Intern Med 2013;173:787.

11. Heyland DK, Barwich D, Pichora D, et al. Failure to engage hospitalized elderly patients and their families in advance care planning. FAMA Intern Med 2013;173:778-87.

12. Hart JL, Harhay MO, Gabler NB, et al. Variability among US intensive care units in managing the care of patients admitted with preexisting limits on life-sustaining therapies. FAMA Intern Med 2015;175:1019-26.

13. Khandelwal N, Kross EK, Engelberg RA, et al. Estimating the effect of palliative care interventions and advance care planning on ICU utilization: a systematic review. Crit Care Med 2015;43:1102-11.

14. Quill CM, Ratcliffe SJ, Harhay MO, et al. Variation in decisions to forgo life-sustaining therapies in US ICUs. Chest 2014;146:573-82.

15. Fried TR, Stein M, O'Sullivan P, et al. Limits of patient autonomy. Physician attitudes and practices regarding life-sustaining treatments and euthanasia. Arch Intern Med 1993;153:722-8.

16. Weiss A, Downar J. Ontario hospitals are not using palliative care performance indicators in their balanced scorecards. 7 Pain Symptom Manage 2013;46:e1-5.

17. Azoulay E, Metnitz B, Sprung C, et al. End-of-life practices in 282 intensive care units: data from the SAPS 3 database. Intensive Care Med 2009; 35:623-30.

18. Garland A, Connors AF Jr. Physicians' influence over decisions to forego life support. 7 Palliat Med 2007;10:1298-305.

19. Fawole OA, Dy SM, Wilson RF, et al. A systematic review of communication quality improvement interventions for patients with advanced and serious illness. 7 Gen Intern Med 2013;28:570-7.

20. Mattison ML, Rudolph JL, Kiely DK, et al. Nursing home patients in the intensive care unit: Risk factors for mortality. Crit Care Med 2006;34:2583-7.

21. Heyland DK, Dodek P, You JJ, et al. Validation of quality indicators for end-of-life communication: results of a multicentre survey. CMAJ 2017; 189:E980-9.

22. Roussel A, Al-Attar N, Alkhoder S, et al. Outcomes of percutaneous femoral cannulation for venoarterial extracorporeal membrane oxygenation support. Eur Heart 7 Acute Cardiovasc Care 2012;1:111-4.

23. Huesch MD, Foy A, Brehm C. Survival outcomes following the use of extracorporeal membrane oxygenation as a rescue technology in critically ill patients: results from Pennsylvania 2007-2015. Crit Care Med 2018; 46:e87-90.

24. Sanaiha Y, Bailey K, Downey P, et al. Trends in mortality and resource utilization for extracorporeal membrane oxygenation in the United States: 20082014. Surgery 2019;165:381-8.

25. Manitoba population report June 1, 2018: Manitoba health, seniors and active living. Winnipeg: Manitoba Health, Healthy Living and Seniors; 2018. Available: www.gov.mb.ca/health/population/pr2018.pdf (accessed 2019 Oct. 10).

26. Garland A, Fransoo R, Olafson $\mathrm{K}$, et al. The epidemiology and outcomes of critical illness in Manitoba. Winnipeg: University of Manitoba; 2012. Available: http://mchp-appserv.cpe.umanitoba.ca/reference/MCHP_ICU_ Report_WEB_\%2820120403\%29.pdf (accessed 2017 Sept. 26).

27. Ock M, Lee SI, Jo MW, et al. Assessing reliability of medical record reviews for the detection of hospital adverse events. 7 Prev Med Public Health 2015;48:239-48.

28. Teasdale G, Jennett B. Assessment of coma and impaired consciousness. Lancet 1974;2:81-4.

29. Knaus WA, Draper EA, Zimmerman JE. APACHE II: a severity of disease classification system. Crit Care Med 1985;13:818-29.
30. Garland A, Olafson K, Ramsey C, et al. Distinct determinants of long-term and short-term survival in critical illness. Intensive Care Med 2014;40:1097-105.

31. Mustard CA, Derksen S, Berthelot JM, et al. Assessing ecologic proxies for household income: a comparison of household and neighbourhood level income measures in the study of population health status. Health Place 1999;5:157-71.

32. Advance care planning: have a say in your health care. Winnipeg: Winnipeg Regional Health Authority; 2018. Available: https://professionals.wrha.mb.ca/ files/acp-workbook.pdf (accessed 2020 May 24).

33. Fox J. Regression diagnostics. London (UK): Sage Publications; 1991.

34. Marrie RA, Dawson NV, Garland A. Quantile regression and restricted cubic splines are useful for exploring relationships between continuous variables. 7 Clin Epidemiol 2009;62:511-7.e1.

35. Newson R. Frequentist q-values for multiple-test procedures. Stata 72010 ; 10:568-84.

36. Scheunemann LP, Ernecoff NC, Buddadhumaruk P, et al. Clinician-family communication about patients' values and preferences in intensive care units. 7AMA Intern Med 2019;179:676-84.

37. Wachterman MW, Pilver C, Smith D, et al. Quality of end-of-life care provided to patients with different serious illnesses. 7AMA Intern Med 2016; 176:1095-102.

38. Thompson BT, Cox PN, Antonelli M, et al. Challenges in end-of-life care in the ICU: statement of the 5 th International Consensus Conference in Critical Care: Brussels, Belgium, April 2003: executive summary. Crit Care Med 2004;32:1781-4.

39. Kelley MA. Predictive scoring systems in the intensive care unit. In: Manaker S, editor. Waltham (MA): UpToDate; 2020.

40. You JJ, Dodek P, Lamontagne F, et al. What really matters in end-of-life discussions? Perspectives of patients in hospital with serious illness and their families. CMAF 2014;186:E679-87.

41. Fried TR, Bradley EH, Towle VR, et al. Understanding the treatment preferences of seriously ill patients. NEngl f Med 2002;346:1061-66.

42. Wessman BT, Sona C, Schallom M. Improving caregivers' perceptions regarding patient goals of care/end-of-life issues for the multidisciplinary critical care team. F Intensive Care Med 2017;32:68-76.

43. Kon AA, Davidson JE, Morrison W, et al. Shared decision-making in ICUs: an American College of Critical Care Medicine and American Thoracic Society Policy Statement. Crit Care Med 2016;44:188-201.

44. Chen C, Michaels J, Meeker MA. Family outcomes and perceptions of endof-life care in the intensive care unit: a mixed-methods review. 7 Palliat Care 2020;35:143-53.

45. Brooks LA, Manias E, Nicholson P. Barriers, enablers and challenges to initiating end-of-life care in an Australian intensive care unit context. Aust Crit Care 2017;30:161-6.

46. Visser M, Deliens L, Houttekier D. Physician-related barriers to communication and patient- and family-centred decision-making towards the end of life in intensive care: a systematic review. Crit Care 2014;18:604.

47. Biskup E, Cai F, Vetter M, et al. Oncological patients in the intensive care unit: prognosis, decision-making, therapies and end-of-life care. Swiss Med Wkly 2017;147:w14481.

Affiliations: Physician Assistant Education Program (Pham), University of Manitoba; Winnipeg Regional Health Authority (Pham); Departments of Internal Medicine and Community Health Sciences (Garland), University of Manitoba, Winnipeg, Man.

Contributors: Both authors contributed to the conception and design of the work. Tammy Phan acquired the data, which both authors analyzed and interpreted. Tammy Phan drafted the manuscript, which Allan Garland revised critically for important intellectual content. Both authors gave final approval of the version to be published and agreed to be accountable for all aspects of the work.

Funding: This research was funded by the Department of Internal Medicine, University of Manitoba.

Content licence: This is an Open Access article distributed in accordance with the terms of the Creative Commons Attribution (CC BY-NC-ND 4.0) licence, which permits use, distribution and reproduction in any medium, provided that the original publication is properly cited, the use is noncommercial (i.e., research or educational use), and no modifications or adaptations are made. See: https://creativecommons.org/licenses/by-nc-nd/4.0/

Data sharing: The source data for this study are not available for sharing, as the data custodian is the Winnipeg Regional Health Authority. Processed data generated in this study are available for use by other researchers for educational and research purposes upon request to the author.

Supplemental information: For reviewer comments and the original submission of this manuscript, please see www.cmajopen.ca/content/9/2/ E570/suppl/DC1. 